\title{
The Relationship between Access to Microfinance, Health-Seeking Behaviour and Health Service Uses: Evidence from Bangladesh
}

\begin{abstract}
This paper examines the extent to which participation in microfinance programs improves health service uses and health-seeking behaviour of participants. The study collects and analyses data from 439 households across 20 villages of four districts covered by three popular microfinance programs in Bangladesh. Our results suggest that participation in a microfinance program is positively associated with improvements in health services uses and health-seeking behaviour. Participation in microfinance programs is found to be associated with significant improvement in three health-related issues: antenatal care, diarrhoea remedial, and immunisation. A positive association between participation in microfinance and other health service uses is also found with weak statistical evidence.
\end{abstract}

Keywords: Microfinance, health-seeking behaviour, health service, Bangladesh.

\section{Introduction}

Bangladesh has played a pivotal role in the movement of microfinance and has shown the world that the poor are creditworthy enough to repay the debt and benefited from financial services (Faruqee \& Badruddoza, 2011). Thus, microfinance institutions (MFIs) have become dominant financial service providers for the poor who cannot access to formal financial institutions in some parts of the world, including Bangladesh with about 1000 listed MFIs (InM, 2015). Apart from financial services, MFIs also provide other development activities, including primary health care to their members. Health services are a natural extension of MFIs' mission to provide financial security and social protection to their clients. Also, healthier 
clients better serve the microfinance institutions' goals of growth and long-term viability (Leatherman and Dunford, 2010).

The evidence on the extent to which participation in microfinance programs affects health behaviour of their participants is scant. A few papers investigated the impacts of microfinance on child health and women health in Indonesia, Latin America, Africa (DeLoach and Lamanna, 2011; Collier, Tesfaye et al., 2014; Geissler and Leatherman, 2015). This study contributes to the literature by conducting a household survey to examine the effects of microfinance on health behaviour of participants in four popular MFIs in Bangladesh.

The remaining of the paper is structured as follows: Section 2 presents a brief review of literature; Section 3 describes the methods; Section 4 displays survey and data; Section 5 discusses results, and Section 6 concludes the paper.

\section{Brief Review of Literature}

Microfinance is expected to influence health-seeking behaviour and health outcomes directly by the ability to pay for health-related services, or indirectly by improving people's economic status and hence increase health inputs (e.g., nutritious food and leisure time). However, only a few previous studies examined the impacts of microfinance on health-seeking behaviour and access to health services (Ahmed, 2001; Ahmed et al., 2005). For example, Ahmed (2001) examined the effects of microfinance on morbidity prevalence, illness profiles and health-seeking behaviour of ethnic groups. Ahmed et al. (2005) found positive benefits of integration of health-related activities in development interventions such as microfinance and found the difference among the ethnic groups.

Despite the limited studies on microfinance and health-seeking behaviour, there is a considerable number of studies on the other aspects of health-related issues and microfinance participation. Hadi (2001), and Strobach and Zaumseil (2007) suggested that microfinance had 
a positive impact on promoting health knowledge among the participants. Other studies revealed the high magnitude of the positive association between microfinance participation and health outcomes (Amin, Shah et al., 2010; Leatherman and Dunford, 2010). Leatherman and Dunford (2010) also found that MFIs were associated with an improvement in the treatment of diarrheal diseases in the Dominican Republic. Likewise, MkNelly and Dunford (1999) found that microfinance was related to better maternal health and nutrition practices in Bolivia. A qualitative study, conducted in Burkina Faso by Hennink and McFarland (2013), showed that microfinance enhanced the health behaviour and health expenditure choices of women. In Ghana, De La Cruz et al. (2009) found that microfinance institutions effectively contributed to the community and national malaria initiatives by increasing knowledge, leading to increased insecticide-treated bed net ownership and use by vulnerable members of the households (particularly pregnant women). Littlefield et al., (2003) also provided specific evidence for the impact of microfinance on health and concluded: "households of microfinance clients appear to have better nutrition, health practices and health outcomes than comparable non-client households" (p.4). Hamid, Roberts et al. (2011) investigated on Grameen Bank (GB), the largest MFI in Bangladesh, and found that adding micro health insurance to the microfinance schemes improved health outcomes of participants.

Moreover, some of the studies dealt with participation in microcredit and its impact on food security, dietary diversity and health shocks. For example, Bidisha et al.( 2017) found that microcredit improved food security, dietary diversity, income as well as smoothed consumption, which thus contributed to eradicate hunger and poverty. A study found that households with access to microcredit appeared to be better able to cope with adverse effects of health shocks, and the significant effects were observed in both short run through direct consumption and long-run through reducing labour substitution (Thanh \& Duong, 2017). 
Overall, previous literature focused on health knowledge or awareness and health improvement and outcomes rather than examining health-seeking behaviour and access to health services.

\section{Methods}

Conceptually, the relationship between microfinance and health-related behaviour can be explained by employing a household economic portfolio model originally developed by Cohen et al. (1996). The model provides the interrelationship between resources, activities and outcomes of households, which allows us to examine the impact of social interventions such as microfinance as it will affect outcomes via an increase in household financial resources. Based on this framework, the effects of participation in microfinance on health-seeking behaviour and access to health services are created via changes in attitudes, and hence healthrelated activities of the households. Other factors that may determine the relationship between microfinance access and health-related outcomes of households include characteristics of households and villages. Thus, a general specification of this relationship is:

$$
h_{i j}=\beta_{0}+\beta_{1} M F_{i j}+\beta_{2} X_{i j}+\beta_{3} V_{j}+\varepsilon_{i j}
$$

where, $h_{i j}$ represents changes in health seeking behaviour of the household $i$ in village $\mathrm{j}$ after joining microfinance, in which one presents improvement and zero otherwise. The term $M F_{i j}$ represents the participation of households in microfinance; $X_{i j}$ is the household characteristics; $V_{j}$ is the set of village characteristics; $\varepsilon_{i j}$ is the random errors term; and $\beta_{1}, \beta_{2}$ and $\beta_{3}$ are parameters to be estimated.

Since the outcome variable as coded as binary ( 1 if the household improves health and sanitation after participating in a microfinance program and 0 otherwise), we choose logistic regressions to estimate the above equation. The main advantage of this regression is 
that the selected type of parameters (odd-ratio) is easy to interpret. We also apply robust estimation of standard errors to consider the presence of unknown heteroskedasticity.

\section{Survey and Data}

Bangladesh is the birthplace of the modern microfinance movement, and the country remains the world's capital of microfinance with more than 1000 registered MFIs. However, more than $70 \%$ of the Bangladesh microfinance market is covered by the "big four" major MFI: the Grameen Bank, the Bangladesh Rural Advancement Committee, Association for Social Advancement and Proshika. Apart from credits, these MFIs have pioneered in providing various other services such as micro-insurance, savings and other integrated development projects. They also lead the way in applying innovations such as mobile phone technology in microfinance services.

\subsection{Sample selection}

The four districts of Bangladesh were selected for the field survey using the main criterion that there must be a Micro Finance Institutions (MFI) with clear eligibility criteria in the district. Three NGOs were selected by applying a purposive sampling technique. The Development Initiative for Social Advancement (DISA) was chosen purposively because the organization received the first national promising MFIs award in the year 2009 from the Palli Karma- Sahayak Foundation (PKSF). The Grameen Bank (GB) and the Bangladesh Rural Advancement Committee (BRAC) were selected as they were the largest and most renowned MFIs in Bangladesh.

Member-households were sampled randomly from a list of microfinance members in each village. It was planned to select 25 households per village. However some households could not be found or had no adult at home and hence could not be 
interviewed. This sample size provides a strong statistical power of $99.5 \%$ (i.e., TypeII error is $0.5 \%$ ) using the pwr package in $\mathrm{R}$ (Champely et al., 2018) with the following assumptions:

a) the Cohen's f2 effect size (Selya et al., 2012), which is defined as the ratio of explained variance by the model over the unexplained variance, is 0.1 ;

b) statistical significant level (Type-I error) is $1 \%$; and

c) 10 independent variables (e.g., age, gender, education, occupation, income) will be used in regressions analysis.

Since the observed number of eligible households in each village was about 100, a sample rate of $25 \%$ was representative and feasible to conduct the interviews. Thus, the total number of households interviewed was 439, or about 22 households per village. It is noteworthy to mention that although most of the household heads were male, the respondents of the survey were primarily women who were engaged with microfinance. The necessary information regarding the amount of credit disbursement, the date of joining and the nature of membership of the participants were supplied by members of the selected microfinance institutions. In order to increase the efficiency of sampling, the choice-based sampling technique was applied (i.e., eligible households were over-sampled in both member and nonmember villages). This sampling approach allowed us to obtain a representative sample with least cost associated with data collection (Lancaster \& Imbens, 1991). In each village, 3 to 4 non-member households were selected and the remaining 18 to 19 households were members. 


\subsection{Variable selection}

\section{$\underline{\text { Dependent Variables }}$}

The dependent variables used in this study are health inputs, access to health service and health-seeking behaviour of the households. We measured 'health seeking behaviour' and 'health input and service' by antenatal care facilities, immunization, diarrhoea remedies for children, family planning services, maternal care services and malaria/TB treatment. We used sources of drinking water and toilet condition as a measure of health input, as evidence (Esmat Ara and Seddiky, 2015; Al Mamun and Adaikalam, 2011) suggested that these two factors are very important determinants of health status in low-income countries like Bangladesh. Changes in health-seeking behaviour and health inputs were measured by the extent of change occurred in nine selected dimensions of health behaviour, health services and health input of the households because of their involvement with the microfinance program of the selected MFIs.

The sources of drinking water status of the households comprised three items namely 'deep tube well', 'shallow tube well', and 'river water'. These options were given in the order of water quality (e.g., the deep tube is better than the shallow tube, which in turn, is better than the river water). An improvement in sources of drinking water of a respondent had been determined by the change to a better water quality sources (e.g., from 'the river' to 'the shallow tube', or from 'the shallow tube' to 'the deep tube') after joining the microfinance program.

The toilet condition of the respondents comprised three items namely, 'full sanitary', 'half sanitary', and 'open'. These options also listed in the order of sanitation. Thus, an improvement indicates the change towards a better sanitation choice of the toilet after joining the microfinance program (e.g., from the half to the full sanitation, or from the open to the half sanitation). 
The health-seeking behaviour and health service, namely 'antenatal care facilities provided', 'immunization provided', 'diarrhoeal remedies', 'family planning services', 'maternal care services', 'malaria/TB treatment' and 'medicines accessibility' of the respondents comprised from two 'yes' and 'no' answers. An improvement in these variables reflects the change from 'no' to 'yes' in the response after joining the microfinance program (e.g., from having no family planning to practice family planning).

\section{$\underline{\text { Independent Variables }}$}

In this study, our main independent variable of interest was the participation of households in microfinance programs offered by the Grameen Bank, BRAC and DISA which was measured by the duration of involvement with the microfinance program. This variable reflects the potential cumulative effects of participating in microfinance. We expected that households participate in microfinance program for the longer period will have more positive effects. Other independent variables included in the analysis were a log of household income per adult equivalent, the age of the household head, ethnic minority status, education of household head, education of spouse, occupation, types of employment of the household head and spouse, number of household member and dependency ratio. In addition to these variables, village level illiteracy rates, distance to the health centre, wheat prices and casual labour rate were used to control for village characteristics. Theoretically, these variables were expected to influence the household's decision to health-seeking behaviour and health service use.

\subsection{Descriptive statistics}

Table 1 presents health input, service and health-seeking behaviour of the sample respondents and the percentage distribution of these dependent variables in the context of before and after joining the microfinance operations. Table 1 shows that $43 \%$ of the households 
use shallow tube-well as a source of drinking water before joining the microfinance programs (MP). The number has reduced by $10 \%$, and the proportion of households using deep tube-well has increased by $12 \%$ after joining microfinance programs. On the other hand, $30 \%$ of respondents have used full sanitary latrine before joining the microfinance while this figure increases by $99 \%$ after joining the microfinance program which could refer to outstanding development. Similarly, in the case of providing antenatal care facilities, $25 \%$ of respondents are provided with this services before joining microfinance programs while the number increases by $145 \%$ after joining the MP which shows tremendous improvement. The scenario of immunisation has turned out to be better after joining microfinance. Table 1 shows a $28 \%$ improvement in immunisation after the joining microfinance. A high increase $(67 \%)$ on any diarrhoea remedies for children has been revealed after joining the microfinance program. Table 1 also shows that after joining the microfinance program, almost $60 \%$ of participants receive maternal care services which are $106 \%$ higher than before joining the microfinance operations.

Similarly, the number of participants who received family planning services has also increased by $87 \%$ after joining the microfinance program. The contribution of microfinance towards malaria/TB treatment has found to be $108 \%$ more than before joining the microfinance program. A very significant portion of improvement has been made in case of medicines accessibility/ affordability to cure diseases (77.7\%) after joining the microfinance program which is $150 \%$ more than before joining the program. This can be thought as a positive transition of their lives. 
Table 1. Descriptive Statistics of Dependent Variables

\begin{tabular}{|c|c|c|c|c|c|c|}
\hline \multirow[t]{2}{*}{ Variable } & \multirow[t]{2}{*}{ Range } & \multicolumn{2}{|c|}{ Before Joining MP } & \multicolumn{2}{|c|}{ After Joining MP } & \multirow{2}{*}{$\begin{array}{c}\text { Wilcoxon } \\
\text { test } \\
\text { (p-value) }\end{array}$} \\
\hline & & $\mathrm{N}$ & $\%$ & $\mathrm{~N}$ & $\%$ & \\
\hline \multicolumn{7}{|l|}{ Health Input } \\
\hline Sources of drinking & Deep Tube $=1$ & 194 & 53.3 & 218 & 59.9 & 0.000 \\
\hline \multirow[t]{2}{*}{ water } & Shallow $=2$ & 156 & 42.9 & 140 & 38.5 & \\
\hline & River $=3$ & 14 & 3.8 & 6 & 1.6 & \\
\hline \multirow[t]{3}{*}{ Toilet condition } & Full sanitary=1 & 110 & 30.2 & 219 & 60.2 & 0.000 \\
\hline & Half sanitary $=2$ & 185 & 50.8 & 135 & 37.1 & \\
\hline & Open $=3$ & 69 & 19.0 & 10 & 2.7 & \\
\hline \multicolumn{7}{|c|}{ Health Seeking Behaviour and Health Service } \\
\hline Any antenatal care & Yes-1 & 92 & 25.3 & 225 & 61.8 & 0.000 \\
\hline facilities provided $^{*}$ & $\mathrm{No}=0$ & 272 & 74.7 & 139 & 38.2 & \\
\hline Any immunization & Yes $=1$ & 249 & 68.4 & 318 & 87.4 & 0.000 \\
\hline provided & $\mathrm{No}=0$ & 115 & 31.6 & 46 & 12.6 & \\
\hline Any kind of diarrhoea & Yes $=1$ & 178 & 48.9 & 297 & 81.6 & 0.000 \\
\hline remedies for children & $\mathrm{No}=0$ & 186 & 51.1 & 67 & 18.4 & \\
\hline Any kind of family & Yes $=1$ & 151 & 41.5 & 283 & 77.7 & 0.000 \\
\hline $\begin{array}{l}\text { planning services } \\
\text { provided }\end{array}$ & $\mathrm{No}=0$ & 213 & 58.5 & 81 & 22.3 & \\
\hline Any kind of maternal & Yes $=1$ & 104 & 28.6 & 214 & 58.8 & 0.000 \\
\hline care services received & $\mathrm{No}=0$ & 260 & 71.4 & 150 & 41.2 & \\
\hline \multirow[t]{2}{*}{ Malaria/TB treatment } & Yes $=1$ & 91 & 25.0 & 189 & 51.9 & 0.000 \\
\hline & $\mathrm{No}=0$ & 273 & 75.0 & 175 & 48.1 & \\
\hline Medicines & Yes $=1$ & 113 & 31.0 & 283 & 77.7 & 0.000 \\
\hline $\begin{array}{l}\text { accessible/affordable } \\
\text { for cure diseases }\end{array}$ & $\mathrm{No}=0$ & 251 & 69.0 & 81 & 22.3 & \\
\hline
\end{tabular}

Respondents' health input, health services and health seeking behaviour are assessed by sources of drinking water, toilet condition, antenatal care, immunisation situation, diarrhoea remedies, family planning facilities, maternal care services, malaria treatment and medicines affordability. Since all variables of interest are categorical, we use the Wilcoxon test to examine the differences in their median before and after joining the microfinance program. The test shows that microfinance participation is associated with significant changes in all variables of interests. In particular, Table 1 shows that after joining the microfinance program there are significant changes in the situation of sources of drinking water although the 
magnitude of changes is small. However, participation in microfinance program is associated with substantial improvement in toilet condition (the rate of the fully sanitary toilet is about double).

About the antenatal care facilities provided, 225 out of 364 respondents reportthat the antenatal care facilities are better than before joining the program. The rate of immunization has been improved substantially, which is almost $28 \%$ more compared to the previous situation, due to participation in microfinance program. There is also a significant association between participation in microfinance program and diarrhoeal remedies for children with the rate of treatment doubled.

Among other health-seeking behaviour and health service related variables, there is also a significant association between participation in microfinance and family planning services, maternal care services, malaria/TB treatment and medicines accessibility. The findings from this study indicate that there is a substantial improvement on the issues mentioned above after joining the microfinance program.

The descriptive statistics of the independent variables, presented in Table 2, show that the average age of the household head is 40 years, and 26 per cent of the household heads have secondary or higher level of education. The average household size is about 5 , and the average number of working age household member is about 3. Among the households surveyed, $12 \%$ of the households are from an ethnic minority group. Further to note that $43 \%$ of the households belong to unskilled occupation (farmers or low skills) whereas $77 \%$ of the households possess full-time employment. It is also revealed from the analysis that the total number of microfinance member is having with an average 31 months in microfinance programs. The mean values of selected welfare indicators such as income per adult equivalent are BDT 97,978 per year (equivalent to US\$ 1260). 
Table 2. Descriptive Statistics of Independent Variables

\begin{tabular}{llrr}
\hline Variables & Unit/ Description & $\underline{\text { Mean }}$ & $\underline{\text { SD }}$ \\
\cline { 2 - 4 } & & & \\
\hline Household characteristics & & 40.21 & 7.87 \\
Age of household head & Years & 0.12 & 0.33 \\
Ethnic minority & Yes=1 & 0.26 & 0.44 \\
Education level & Secondary or above=1 & 0.43 & 0.50 \\
Occupation & Farmers or low skills $=1$ & 0.77 & 0.42 \\
Type of employment & Full Time =1 & 4.79 & 1.29 \\
Household size & Persons & 2.84 & 1.17 \\
People in labour age & Persons & 31.66 & 28.28 \\
Duration in microfinance & Months & 97,978 & 55,285 \\
Income per adult & BDT/year & & \\
equivalent & & 19.11 & 11.99 \\
Village Characteristics & & 12.03 & 26.05 \\
Illiteracy rate & Percentage & & \\
Distance to the health & Kilometre & 23.40 & 5.05 \\
centre & & 300 & 75 \\
Wheat price & *BDT/kg & BDT/day & \\
Casual labour & & & \\
\hline
\end{tabular}

Notes: Source: Authors' calculations based on the Field Survey, 2014; N=439; *BDT = Bangladesh Taka

Table 2 also shows that on an average the illiteracy rate in the village is $19 \%$. The average distance between the health centre and the village is 12 kilometres. Further to reveal that the average wheat price is $23 \mathrm{BDT} / \mathrm{kg}$, whereas the casual labour price is $300 \mathrm{BDT} /$ day in the surveyed villages.

\section{Results and Discussions}

The detailed results of the logistic regressions are presented in Table 3. Overall, access to the microfinance is positively and significantly associated with an improvement in antenatal care, immunisation, and treatment of diarrhoea. Also, the effects seem to strengthen with the 
duration of participation in a microfinance program. However, the effect of microfinance on the other indicators is not clear, and inconsistent.

\section{Immunization Provided}

Our results show that participation in a microfinance program significantly increases the odds of full immunization. In particular, the duration effect of microfinance on immunization is significant at $1 \%$ level, which suggests that the odds of improving immunization are 4:1 for members who joined microfinance program (MP) for 2 years, 3:1 for members who joined the MP for 3 years, and 4:1 for members who joined the MP for 4 years and beyond compared to the reference group (member for 1 year or less). The study also reveals that heads of households who have a secondary school education are more likely to have improved immunisation levels for their children, whereas spouse's secondary education level are negatively associated with the improvements in immunisation. Particularly, household head and spouse with secondary schooling have the odds of improving immunization by $2: 1$ and $0.5: 1$, respectively. Moreover, among the village characteristic variables, the village illiteracy rate, the distance to the health centre and wheat prices are significantly and negatively associated (as the odds ratios are less than 1) with improved immunization status. In particular, one percentage point increases in the village illiteracy is associated with the odds of improving immunization by $0.94: 1$, whereas the marginal effects of distance to the health centre and the wheat price are associated with the odds of $0.96: 1$ and $0.86: 1$, respectively. 
Table 3: Effects of microfinance on health input, health-seeking behaviour and health services

\begin{tabular}{|c|c|c|c|c|c|c|c|c|c|c|c|c|c|c|c|c|c|c|}
\hline \multirow{2}{*}{$\begin{array}{l}\text { Independent } \\
\text { variables }\end{array}$} & \multicolumn{2}{|c|}{ Immunization } & \multicolumn{2}{|c|}{ Diarrhoea } & \multicolumn{2}{|c|}{ Antenatal care } & \multicolumn{2}{|c|}{ Maternal care } & \multicolumn{2}{|c|}{ Family planning } & \multicolumn{2}{|c|}{ Drinking water } & \multicolumn{2}{|c|}{ Toilet use } & \multicolumn{2}{|c|}{ Malaria/TB } & \multicolumn{2}{|c|}{ Medicines } \\
\hline & OR & SE & OR & SE & OR & SE & OR & SE & OR & SE & OR & SE & OR & SE & OR & SE & OR & SE \\
\hline Join MP for 2 years & $4.04 * * *$ & 1.94 & $3.66^{* * *}$ & 1.42 & $2.72 * * *$ & 1.04 & $2.01 *$ & 0.76 & $2.03 * *$ & 0.72 & 1.94 & 0.95 & 1.42 & 0.80 & 0.95 & 0.37 & 0.63 & 0.21 \\
\hline Join MP for 3 years & $3.82 * * *$ & 1.86 & $2.14^{*}$ & 0.83 & $3.16^{* * *}$ & 1.18 & $2.00^{*}$ & 0.75 & 1.30 & 0.46 & $2.90^{* *}$ & 1.55 & 2.07 & 1.30 & $1.90^{*}$ & 0.71 & 0.66 & 0.22 \\
\hline Join MP for 4 years or more & $4.26^{* * *}$ & 2.25 & $2.11^{*}$ & 0.93 & $3.51^{* * * *}$ & 1.48 & 1.15 & 0.51 & 1.38 & 0.56 & 0.78 & 0.39 & 1.51 & 1.01 & $2.37 * *$ & 1.00 & $0.50^{*}$ & 0.19 \\
\hline \multicolumn{19}{|l|}{ Household characteristics } \\
\hline Age of household head (years) & 1.00 & 0.02 & $1.03 *$ & 0.02 & 1.00 & 0.02 & 1.00 & 0.02 & $1.05 * * *$ & 0.02 & 1.02 & 0.03 & 0.96 & 0.03 & 1.00 & 0.02 & 1.01 & 0.02 \\
\hline Minority ethnics (minority=1) & 0.62 & 0.28 & $0.25^{* * *}$ & 0.12 & 1.36 & 0.49 & 0.74 & 0.30 & $0.36 * *$ & 0.15 & 1.92 & 1.11 & 2.79 & 2.20 & $0.36 * *$ & 0.17 & $0.38^{* * *}$ & 0.14 \\
\hline HH head Secondary school & $2.13^{* *}$ & 0.75 & 1.64 & 0.54 & $1.82 *$ & 0.58 & $3.08^{* * *}$ & 1.06 & $1.80^{*}$ & 0.57 & 1.20 & 0.59 & 3.46 & 2.83 & 1.42 & 0.47 & $1.95 * *$ & 0.61 \\
\hline HH head High School & 1.74 & 1.45 & 0.84 & 0.71 & 0.22 & 0.25 & $4.11^{*}$ & 3.22 & 1.19 & 0.90 & 1.64 & 1.89 & 1.23 & 1.58 & 0.82 & 0.66 & 1.39 & 1.04 \\
\hline HH head College/University & 1.60 & 2.02 & 1.35 & 1.58 & 0.61 & 0.78 & 1.24 & 1.61 & 0.88 & 1.03 & & & & & 0.80 & 1.00 & 0.58 & 0.71 \\
\hline Education of spouse Secondary & $0.51^{*}$ & 0.19 & 0.61 & 0.20 & $0.46^{* *}$ & 0.15 & $0.29^{* * *}$ & 0.11 & 0.68 & 0.21 & 1.33 & 0.62 & 1.76 & 1.17 & 0.81 & 0.26 & $0.49 * *$ & 0.15 \\
\hline Education of spouse High school & 0.71 & 0.50 & 1.30 & 0.87 & 0.45 & 0.33 & 0.40 & 0.27 & 1.73 & 1.10 & 1.80 & 2.09 & 0.66 & 0.85 & 1.03 & 0.67 & 0.53 & 0.34 \\
\hline Occupation (farmers/labourers=1) & 0.74 & 0.20 & $0.59 * *$ & 0.15 & 0.97 & 0.23 & 1.29 & 0.32 & 0.88 & 0.21 & 0.76 & 0.27 & 0.80 & 0.34 & $0.63 *$ & 0.16 & 1.11 & 0.25 \\
\hline Type of employment(full-time $=1^{ \pm}$) & 1.40 & 0.48 & $2.80^{* * *}$ & 0.91 & 0.80 & 0.23 & $0.61^{*}$ & 0.18 & 1.26 & 0.37 & 1.40 & 0.55 & 1.69 & 0.81 & 0.96 & 0.29 & 1.14 & 0.31 \\
\hline Number of people in the family & 0.83 & 0.10 & $0.84 *$ & 0.09 & 0.95 & 0.10 & $0.82 *$ & 0.09 & $0.83 *$ & 0.08 & 0.98 & 0.14 & 1.03 & 0.17 & $0.80 * *$ & 0.09 & 0.92 & 0.09 \\
\hline Dependency ratio & 0.49 & 0.41 & 1.46 & 1.12 & 0.98 & 0.72 & 1.43 & 1.12 & $4.08^{*}$ & 3.12 & 2.80 & 2.90 & 6.38 & 7.87 & 0.94 & 0.74 & 2.46 & 1.76 \\
\hline Log of income per person & 0.88 & 0.23 & 1.13 & 0.27 & $2.23 * * *$ & 0.20 & $1.91 * *$ & 0.49 & 1.44 & 0.34 & 0.74 & 0.24 & 0.65 & 0.27 & 1.00 & 0.24 & 1.14 & 0.25 \\
\hline \multicolumn{19}{|l|}{ Village characteristics } \\
\hline Illiteracy rate (\%) & $0.94 * * *$ & 0.02 & $0.94 *$ & 0.03 & 0.99 & 0.02 & $0.96^{*}$ & 0.02 & 0.99 & 0.02 & $0.97 *$ & 0.02 & 1.01 & 0.04 & 0.99 & 0.02 & 0.98 & 0.02 \\
\hline Distance to health centre $(\mathrm{km})$ & $0.96^{* *}$ & 0.02 & 0.99 & 0.02 & 0.89 & 0.06 & 0.77 & 0.24 & 0.77 & 0.26 & $0.92^{* * *}$ & 0.02 & $0.91^{* * *}$ & 0.02 & 1.01 & 0.01 & $2.55^{* *}$ & 0.96 \\
\hline Wheat prices (Taka/kg) & $0.86^{* *}$ & 0.05 & 1.06 & 0.09 & 0.95 & 0.06 & 0.90 & 0.07 & 0.90 & 0.07 & $0.81^{* * *}$ & 0.05 & $0.81 * *$ & 0.07 & 1.06 & 0.06 & $0.60^{* * *}$ & 0.07 \\
\hline Casual labour (Taka/days) & 1.01 & 0.01 & 0.99 & 0.01 & 0.99 & 0.01 & 0.99 & 0.01 & 0.99 & 0.01 & 1.01 & 0.01 & 0.99 & 0.01 & $0.98^{* *}$ & 0.01 & $1.03 * * *$ & 0.01 \\
\hline MFI $=$ DISA $^{\#}$ & 0.97 & 0.31 & 0.93 & 0.28 & 1.24 & 0.37 & 1.04 & 0.32 & 1.39 & 0.42 & 0.63 & 0.29 & 0.55 & 0.31 & 1.35 & 0.42 & 0.72 & 0.21 \\
\hline $\mathrm{MFI}=\mathrm{BRAC}^{\#}$ & 0.83 & 0.34 & 0.96 & 0.36 & 1.57 & 0.58 & 1.26 & 0.48 & 1.65 & 0.60 & 0.82 & 0.47 & 1.34 & 1.05 & 1.41 & 0.55 & 0.93 & 0.33 \\
\hline chi2 & 27.38 & & 56.95 & & 43.72 & & 43.07 & & 37.87 & & 16.17 & & 20.77 & & 20.84 & & 22.29 & \\
\hline $\mathrm{p}$ & 0.05 & & 0.00 & & 0.00 & & 0.00 & & 0.00 & & 0.44 & & 0.19 & & 0.23 & & 0.17 & \\
\hline Pseudo R2 & 0.06 & & $0.11 \mathrm{c}$ & & 0.09 & & 0.09 & & 0.078 & & 0.060 & & 0.10 & & 0.048 & & 0.044 & \\
\hline
\end{tabular}




\section{Diarrhoeal remedies}

The results from Table 3 show that participation in the microfinance program significantly improves the odds of 1 remedial therapies to combat diarrhoea. The duration effect of microfinance participation on diarrhoeal remedy is significant at $1 \%$ and $10 \%$ level, respectively. It advises that the odds of improving diarrhoeal remedy are 3:1 for members who joined the MP for two years, 2:1 for members who joined the MP for three years and beyond compared to the reference group (member for one year or less). Among other variables, the age of the household head and their type of employment are also found to be positively associated with improved diarrhoeal remedies; whereas their status as belonging to a minority ethnicity, the occupation of the respondent, and the number of people in the family are significantly and negatively associated with efforts to mitigate diarrhoea. In particular, those who belong to a minority ethnic group have the odds of improving diarrhoeal remedy by $0.25: 1$ when compared with those in majority groups. Also, households with full-time employment have the odds of improving the diarrhoeal remedy by $2.8: 1$ compared to the households with part-time employment. Further, the occupation of the household head and the number of people in the family have the odds of improving the diarrhoeal remedy by $0.59: 1$ and $0.84: 1$, respectively. Moreover, among the village characteristics variables, village illiteracy rate is negatively associated with the diarrhoeal remedy, which suggests that one percentage point increase in the village illiteracy is associated with the odds of improving diarrhoeal remedy by $0.94: 1$, however, it is found to be significant at 5\% level.

\section{Antenatal Care}

Our results show that participation in a microfinance program has a significant positive effect on the antenatal care services provided. In particular, the duration effect of microfinance on the antenatal care is significant at $1 \%$ level, which suggests that the odds of 
improving antenatal care are 2:1 for members who join the MP for two years, 3:1 for members who join the MP for three years and beyond compared to the reference group (being microfinance member for 1 year or less).

Other significant determinants of antenatal care include education of household head and spouse, having a secondary school and income per person. The results show that the antenatal care improves significantly and positively if the head of the household has an education at secondary school level, whereas the level of spousal education (secondary school) is negatively associated with the improved antenatal care. In particular, the head of the household and the spouse of the household head who completed secondary schooling have the odds of improving antenatal care by $1.82: 1$ and $0.46: 1$, respectively. Moreover, income per person is found to be positively associated with receiving the improved antenatal care services. The results show that income per person has the odd of improving antenatal care by $2: 1$, which is significant at $1 \%$ level.

\section{Maternal care}

Table 3 shows that being a member of MP for more than two years but less than four years is positively related with improved maternal care. However, being a member of MFI for four years or more is not found to be statistically significant because, in all likelihood, the mother is no longer in childbearing age. Maternal care is likely to be improved for members who live in a household with heads who have completed secondary school and high school. On the other hand, the association is negative for the households where the spouse has completed secondary school. In particular, household heads with secondary and high schooling have the odds of improving maternal care by $3: 1$ and $4: 1$, respectively, whereas the spouses with secondary schooling have the odds of improving maternal care only by $0.29: 1$. Also, among the other household characteristics, income per person is significantly and positively associated with receiving improved maternal care services, where income has the odds of improving 
maternal care by 2:1. However, the type of employment and the number of people in the family are significantly and negatively associated with the improved maternal care, which indicates that the type of employment and the number of people in the family have the odds of improving the maternal care of $0.61: 1$ and $0.82: 1$, respectively. Moreover, among the village characteristics variables, village illiteracy rate is significantly and negatively associated with maternal care, which suggests that the village illiteracy has only the odds of improving maternal care by $0.96: 1$.

\section{Family Planning services}

Table 3 shows that the length of the duration of participation with the MFI does not have any impact on improvement in family planning services. However, if the duration of membership of MP is higher than one year but less than three years, then it is more likely to improve the odds of accessing family planning services by $2: 1$ (5\% significant). The probable explanation of this result is that senior members of microfinance schemes may be beyond the reproductive age (the average age is 40 years which is in the borderline of maximum reproductive ability), and hence less likely to require family planning. Although the odd-ratios for other years are also favourable (i.e. odds $>1$ ), but it is not statistically significant. Among the other variables, the age of the household head, secondary schooling having been completed by the head of the household, and the dependency ratio are also found to be positively associated with the better family planning services, whereas minority ethnicity and number of people in the family are significantly and negatively associated with improved family planning services. In particular, those who belong to ethnic minority have the odds of improved family planning services by 0.36:1 compared to Muslim. Also, the households with the highest number of people in the family have the odds of improving family planning services by $0.83: 1$, whereas the dependency ratio has the odds of 4:1. Also, household heads with secondary schooling experience a significant improvement in family planning services with the odds of 1.8:1. 


\section{Sources of drinking water}

Our results show that participation in the microfinance program significantly increases the probability of improved sources of drinking water. In particular, the duration effect of microfinance on sources of drinking water is significant at 5\% level, which indicates that the odds of improving the condition of sources of drinking water are 2:1 for members who joined MP for 3 years compared to the reference group (microfinance member for 1 year or less). Moreover, among the village characteristics variables, village illiteracy rate, distance to the health centre and wheat prices of the village are significantly and negatively associated with the condition of drinking water. In particular, the illiteracy rate has the odds of improved drinking water condition of about $0.97: 1$, but it is only significant at $10 \%$ level. Moreover, the distance to the health centre and wheat price have the odds of improving the drinking water condition about $0.92: 1$ and $0.81: 1$, respectively.

\section{Toilet condition}

Table 3 shows that the duration of microfinance membership has no significant effects on the improvement of toilet condition, although the association is positive. The probable reason for this result is that the members have been enjoying the improved toilet facilities before joining the microfinance due to government and nongovernment initiatives that have already been implemented in those villages. Moreover, among the village characteristics, the distance to health centres and the price of wheat in the village are significantly and negatively associated with toilet conditions. In particular, the distance to the health centre has the odds of improving the toilet condition by $0.91: 1$, whereas the wheat price has the odds of about $0.81: 1$. 


\section{Malaria/TB treatment}

The microfinance programs are significantly associated with the increased probability of improving malaria/TB treatment. In particular, the duration effect of MP on malaria/TB treatment is significant at the $5 \%$ level, which indicates that the odds of improving the condition of malaria/TB treatment are 2:1 for members who joined MP for 3 years and beyond compared to the reference group (being microfinance member for 1 year or less). The improvement in access to malaria/TB treatment is less likely to occur if the household has more members and is from ethnic minority status. Those households who belong to the ethnic minority have the odds of improving malaria/TB treatment of $0.36: 1$ compared to the majority groups. Other significant determinants of malaria/TB treatment comprise occupation of the household head and the number of people in the family, which are negatively associated with the improvement of malaria/TB treatment. In particular, the heads of households' occupations as farmers/labourers have the odds to improve malaria/TB treatment of about $0.63: 1$ compared to other groups, whereas the number of people in the family have the odds to improve malaria/TB treatment of about $0.80: 1$. Also, among the village characteristic variables, the casual labour prices are significantly and negatively associated with malaria/TB treatment. Particularly, casual labour prices have the odds of improving malaria/TB treatment at about 0.98:1.

\section{Medicines accessibility}

Our results show that participation in MP has a significant negative effect on the accessibility of medicines. In particular, the odds of improving the accessibility of medicines after joining the microfinance program for four years and beyond is $0.50: 1$ compared to the reference group of those who joined for one year. Also, households from ethnic minority and levels of spousal education of the heads of the household having secondary schooling are less 
likely to have created better access to medicines, whereas household heads with secondary schooling are more likely to have improved access to medicines. The households from the ethnic minority and the variable employment have the odds of improving the accessibility to medicines by $0.38: 1$ when compared to Muslim majority groups. Household heads with secondary school education have the odds of improving access to medicines by about $2: 1$, whereas spouse's education has the odds of improving the accessibility to medicines by about 0.49:1. Moreover, among the village characteristics variables, distance to health centres and casual labour prices are found to be positively associated with the accessibility to medicines, while wheat prices are found to have a negative association. In particular, households with casual labour have the odds of improving access to medicines by about $1.03: 1$, whereas the distance to health centres have the odds of improving access to medicines by about 2.55:1.

\section{Conclusion}

This study has examined the impacts of microfinance activities on health-seeking behaviour and health service uses of the rural households in Bangladesh. We find that the health-seeking behaviour and health services of the households have improved significantly after joining the microfinance program. We recommend that the policymakers related to the health issues in developing countries should enhance their cooperation to achieve the millennium development goals and to strengthen the health system through inter-sectoral programming that utilizes a microfinance platform to reach the poor and underserved populations. Our results on the beneficial health practices among the participants of MP can be used as a starting point for further studies to investigate the links between microfinance and health-seeking behaviour and health services of the rural households. However, we are not able to disentangle, in this study, how much of this improvement in health care and healthseeking behaviour is the result of the activities of MP, or it is a general process of development 
undertaken by the government and policymakers. Furthermore, it is essential for future research to explore whether there is a substantial difference in the health seeking behaviour between the treatment (member) and control (non-member) groups of the MFIs. 


\section{References}

Ahmed, S. M., 2001. Differing health and health-seeking behaviour: ethnic minorities of the Chittagong Hill Tracts, Bangladesh. Asia-Pacific Journal of Public Health 13(2): 100-108.

Ahmed, S. M., A. M. Adams, M. Chowdhury and A. Bhuiya., 2000. Gender, socioeconomic development and health-seeking behaviour in Bangladesh. Social science \& medicine 51(3): 361371.

Ahmed, S. M., A. M. Adams, M. Chowdhury and A. Bhuiya., 2003. Changing health-seeking behaviour in Matlab, Bangladesh: do development interventions matter? Health Policy and Planning 18(3): 306-315.

Ahmed, S. M., M. Petzold, Z. N. Kabir and G. Tomson., 2006. Targeted intervention for the ultra poor in rural Bangladesh: Does it make any difference in their health-seeking behaviour? Social science \& medicine 63(11): 2899-2911.

Ahmed, S. M., G. Tomson, M. Petzold and Z. N. Kabir., 2005. Socioeconomic status overrides age and gender in determining health-seeking behaviour in rural Bangladesh. Bulletin of the World Health Organization 83(2): 109-117.

Al Mamun, A. and J. Adaikalam., 2011. Empirical Investigation on the Effect of Microfinance Program of Amanah Ikhtiar Malaysia on Quality of Life in Urban Peninsular Malaysia. European Journal of Economics, Finance and Administrative Sciences, ISSN: 1450-2275.

Amin, R., M. S. Pierre, A. Ahmed and R. Haq., 2001. Integration of an essential services package (ESP) in child and reproductive health and family planning with a micro-credit program for poor women: experience from a pilot project in rural Bangladesh. World Development 29(9): 1611-1621.

Amin, R., N. M. Shah and S. Becker., 2010. Socioeconomic factors differentiating maternal and child health-seeking behavior in rural Bangladesh: A cross-sectional analysis. Int J Equity Health 9(9): 112.

Barnes, C., G. Gaile and R. Kimbombo., 2001. Impact of three microfinance programs in Uganda. Assessing the Impact of Microenterprise Services (AIMS) Project in association with the Makerere Institute of Social Research (MISR).

BBS, 2006. Preliminary report on household income and expenditure survey - 2005. Dhaka: Planning Division, Ministry of Planning.

Bidisha, S. H., Khan, A., Imran, K., Khondker, B. H., \& Suhrawardy, G. M., 2017. Role of credit in food security and dietary diversity in Bangladesh. Economic Analysis and Policy, 53, 33-45.

Cohen, M., M. A. Chen and E. Dunn., 1996. Household economic portfolios. More info www. eldis. org/vfile/upload/1/document/0708/DOC2932. pdf,(18 November 2010).

Collier, S., M. Tesfaye, T. Henderson, J. Abafita, E. Tarbi, A. Pietras and Z. Chemali., 2014. Microfinance and women's health: an evaluation of women's health behaviors in Jimma, Ethiopia. International Journal of Culture and Mental Health 7(2): 152-161.

CDF and InM, 2013. Bangladesh Microfinance Statistics 2013. Retrieved from www.cdfbd.org Champely, S., Ekstrom, C., Dalgaard, P., Gill, J., Weibelzahl, S., Anandkumar, A., . . . De Rosario, M. H., 2018. Package 'pwr'.

De La Cruz, N., B. Crookston, B. Gray, S. Alder and K. Dearden., 2009. Microfinance against malaria: impact of Freedom from Hunger's malaria education when delivered by rural banks in Ghana. Transactions of the Royal Society of Tropical Medicine and Hygiene 103(12): 1229-1236.

DeLoach, S. B. and E. Lamanna., 2011. Measuring the impact of microfinance on child health outcomes in Indonesia. World Development 39(10): 1808-1819.

Esmat Ara, M. and A. Seddiky., 2015. Impact of Grameen Bank Microcredit Program on the Livelihood Status of Women Beneficiaries in Bangladesh. American International Journal of Research in Humanities, Arts and Social Sciences9(4): 323-332.

Faruqee, RR \& Badruddoza, S., 2011. Microfinance in Bangladesh: Past, Present, and Future.

Occasional Paper. Institute of Microfinance.

Geissler, K. H. and S. Leatherman., 2015. Providing primary health care through integrated microfinance and health services in Latin America. Social Science \& Medicine 132: 30-37. 
Hadi, A., 2001. Promoting health knowledge through micro-credit programmes: experience of BRAC in Bangladesh. Health promotion international 16(3): 219-227.

Hamid, S. A., J. Roberts and P. Mosley., 2011. Evaluating the health effects of micro health insurance placement: Evidence from Bangladesh. World Development 39(3): 399-411.

Hennink, M. and D. A. McFarland., 2013. A delicate web: Household changes in health behaviour enabled by microcredit in Burkina Faso. Global public health 8(2): 144-158.

InM, 2015. Institute of Microfinance. Retrieved from www.inm.org.bd

Koenig, M. A., K. Jamil, P. K. Streatfield, T. Saha, A. Al-Sabir, S. E. Arifeen, K. Hill and Y. Haque., 2007. Maternal health and care-seeking behavior in Bangladesh: findings from a national survey. International Family Planning Perspectives: 75-82.

Lancaster, T \& Imbens, G., 1991. Choice-based sampling: Inference and optimality, University of

Bristol, Department of Economics.

Leatherman, S. and C. Dunford., 2010. Linking health to microfinance to reduce poverty. Bulletin of the World Health Organization 88(6): 470-471.

Littlefield, E., J. Morduch and S. Hashemi., 2003. Is microfinance an effective strategy to reach the Millennium Development Goals? Focus Note 24(2003): 1-11.

MkNelly, B. and C. Dunford., 1999. Impact of credit with education on mothers and their young children's nutrition: CRECER credit with education program in Bolivia. Freedom from Hunger Research Paper 5.

Norwood, C., 2011. Women, microcredit and family planning practices: a case study from rural Ghana. Journal of Asian and African studies 46(2): 169-183.

Pronyk, P. M., J. R. Hargreaves, J. C. Kim, L. A. Morison, G. Phetla, C. Watts, J. Busza and J. D. Porter., 2006. Effect of a structural intervention for the prevention of intimate-partner violence and HIV in rural South Africa: a cluster randomised trial. The lancet 368(9551): 1973-1983.

Quayyum, Z., M. N. U. Khan, T. Quayyum, H. E. Nasreen, M. Chowdhury and T. Ensor., 2013. Can community level interventions have an impact on equity and utilization of maternal health care"Evidence from rural Bangladesh. International journal for equity in health 12(1): 22.

Rahman, M. H., W. H. Mosley, S. Ahmed and H. H. Akhter., 2008. Does service accessibility reduce socioeconomic differentials in maternity care seeking? Evidence from rural Bangladesh. Journal of Biosocial Science 40(01): 19-33.

Rahman, S. A., T. Kielmann, B. McPake and C. Normand., 2012. Healthcare-seeking behaviour among the tribal people of Bangladesh: Can the current health system really meet their needs? Journal of health, population, and nutrition 30(3): 353 .

Smith, S. C., 2002. Village banking and maternal and child health: evidence from Ecuador and Honduras. World Development 30(4): 707-723.

Strobach, T. and M. Zaumseil., 2007. An evaluation of a micro-credit system to promote health knowledge among poor women in Bangladesh. Health promotion international 22(2): 129-136.

Selya, A. S., Rose, J. S., Dierker, L. C., Hedeker, D., \& Mermelstein, R. J., 2012. A practical guide to calculating Cohen's f2, a measure of local effect size, from PROC MIXED. Frontiers in psychology, 3,111 .

Thanh, P. T., \& Duong, P. B., 2017. Health shocks and the mitigating role of microcredit-The case of rural households in Vietnam. Economic Analysis and Policy, 56, 135-147.

World Health Organization, 2005. Retrieved from http://www.who.int/en/ on April, 2015. 